Kalpa Publications in Engineering
Volume 4, 2022, Pages 32-49
Proceedings of International Sym-
posium on Applied Science 2021

\title{
An Iterative Process for a Finite Family of Bregman Totally Quasi-Asymptotically Nonexpansive Mappings and a System of Generalized Mixed Equilibrium Problems in Reflexive Banach Spaces
}

\author{
Trung Hieu Nguyen ${ }^{1 *}$ \\ ${ }^{1}$ Department of Mathematics and Information Technology Teacher Education, \\ Dong Thap University, Cao Lanh, Dong Thap, Vietnam. \\ ngtrunghieudathu.edu.vn
}

\begin{abstract}
The equilibrium problem and its generalizations had a great influence in the development of some branches of pure and applied sciences. The equilibrium problems theory provides a natural and novel approach for some problems arising in nonlinear analysis, physics and engineering, image reconstruction, economics, finance, game theory and optimization. In recent times, there were many methods in order to solve the equilibrium problem and its generalizations. Some authors proposed many iterative methods and studied the convergence of such iterative methods for equilibrium problems and nonexpansive mappings in the setting of Hilbert spaces and Banach spaces. Note that a generalized mixed equilibrium problem is a generalization of an equilibrium problem and a Bregman totally quasi-asymptotically nonexpansive mapping is a generalization of a nonexpansive mapping in reflexive Banach spaces. The purpose of this paper is to combine the parallel method with the Bregman distance and the Bregman projection in order to introduce a new parallel hybrid iterative process which is to find common solutions of a finite family of Bregman totally quasiasymptotically nonexpansive mappings and a system of generalized mixed equilibrium problems. After that, we prove that the proposed iteration strongly converges to the Bregman projection of initial element on the intersection of common fixed point set of a finite family of Bregman totally quasi-asymptotically nonexpansive mappings and the solution set of a system of generalized mixed equilibrium problems in reflexive Banach spaces. As application, we obatin some strong convergence results for a Bregman totally quasi-asymptotically nonexpansive mapping and a generalized mixed
\end{abstract}

${ }^{*}$ Corresponding author 
equilibrium problem in reflexive Banach spaces. These results are extensions and improvements to the main results in $[7,8]$. In addition, a numerical example is provided to illustrate for the obtained result.

Key words: Bregman totally quasi-asymptotically nonexpansive mapping, iterative method, generalized mixed equilibrium problem, reflexive Banach space, strong convergence.

\section{Introduction}

In 2008, Peng and Yao [12] generalized the equilibrium problem to the generalized mixed equilibrium problem. Assume that $W$ is a real Banach space, $\Omega$ is a nonempty, closed and convex subset of $W, W^{*}$ is a the dual space of $W$. Let $f: \Omega \times \Omega \rightarrow \mathbb{R}, \varphi: \Omega \rightarrow \mathbb{R}$ be two functions and $\psi: \Omega \rightarrow W^{*}$ be a mapping. We denote the value of $u^{*} \in W^{*}$ at $u \in X$ by $\left\langle u^{*}, u\right\rangle$. The generalized mixed equilibrium problem (GMEP) is to find $u \in \Omega$ such that

$$
f(u, v)+\langle\psi(u), v-u\rangle+\varphi(v) \geq \varphi(u), \forall v \in \Omega \text {. }
$$

The set of solutions of (GMEP) is denoted by

$$
\operatorname{GMEP}(f, \varphi, \psi)=\{u \in \Omega: f(u, v)+\langle\psi(u), v-u\rangle+\varphi(v) \geq \varphi(u), \forall v \in \Omega\} .
$$

When $\varphi \equiv 0$ and $\psi \equiv 0$, the problem (GMEP) is reduced to the equilibrium problem (EP) which is to find $u \in \Omega$ such that $f(u, v) \geq 0$ for all $v \in \Omega$. In recent times, some authors constructed many iterative methods for finding common solutions of fixed points set of nonlinear mappings and solution set of (EP) or (GMEP) in reflexive Banach spaces with the Bregman distance $[6,10,14,16]$. In 2018, Kazmi et al. [8] extended and improved the main results in [7] from an equilibrium problem and a fixed point problem for an asymptotically quasi- $\phi$-nonexpansive mapping in intermediate sense in uniformly smooth and strictly convex Banach spaces to a generalized equilibrium and fixed point problem for a Bregman relatively nonexpansive mapping in reflexive Banach spaces.

The notion of a Bregman totally quasi-asymptotically nonexpansive mapping is introduced by Chang et al. [5] in 2014. This mapping is a generalization of many mappings which relate to the Bregman distance in reflexive Banach spaces. An interesting work naturally raised is to extend and generalize the existing convergence results to (GMEP) and Bregman totally quasi-asymptotically nonexpansive mappings in reflexive Banach spaces. In this paper, motivated by the iteration processes in $[7,8]$, we introduce a new hybrid iterative method for a finite family of Bregman totally quasiasymptotically nonexpansive mappings and a system of generalized mixed equilibrium problems in reflexive Banach spaces. By using some suitable conditions, we prove that the proposed iteration strongly converges to the Bregman projection of initial element on the intersection of common fixed point set of a finite family of Bregman totally quasi-asymptotically nonexpansive mappings and the solution set of a system of generalized mixed equilibrium problems in reflexive Banach spaces. In addition, a numerical example is given to illustrate for the obtained results.

\section{Preliminaries}

Throughout this paper, we assume that $W$ is a real reflexive Banach space, $\Omega$ is a nonempty, closed and convex subset of $W, W^{*}$ is a the dual space of $W, g: W \rightarrow(-\infty,+\infty]$ is a lower semi 
continuous, convex and proper function, $\operatorname{dom} g=\{u \in W: g(u)<+\infty\}$ is the domain of $g$. For any $u \in \operatorname{int}(\operatorname{dom} g), v \in W$, we denote by

$$
g^{\prime}(u, v)=\lim _{\lambda \rightarrow 0^{+}} \frac{g(u+\lambda v)-g(u)}{\lambda}
$$

the right-hand derivative of $g$ at $u$ in the direction $v$. The function $g$ is called Gâteaux differentiable at $u$ if the limit (1.1) exists for all $v$. Then the gradient of $g$ at $u$ is $\nabla g(u)$, which is defined by $\langle\nabla g(u), v\rangle=g^{\prime}(u, v)$ for all $v \in W$. The function $g$ is called Fréchet differentiable at $u$ if the limit (1.1) is attained uniformly in $\|v\|=1$. The function $g$ is called be uniformly Fréchet differentiable on a subset $\Omega$ of $W$ if the limit (1.1) is attained uniformly for $u \in \Omega$ and $\|v\|=1$.

Remark 2.1. (1) ([1], Theorem 1.8) If $g$ is uniformly Fréchet differentiable, then $g$ is uniformly continuous.

(2) ([1], Proposition 1.1.11). If $g$ is Gâteaux differentiable, then $g$ is bounded on bounded sets if and only if $\nabla g$ is bounded on bounded sets.

(3) ([14], Proposition 1). If $g$ is uniformly Fréchet differentiable and bounded on bounded subsets, then $\nabla g$ is uniformly continuous on bounded subsets of $W^{*}$.

Let $u \in \operatorname{int}(\operatorname{dom} g)$, the Fenchel conjugate of $g$ is the function $g^{*}: W^{*} \rightarrow(-\infty,+\infty]$ defined by $g^{*}\left(u^{*}\right)=\sup \left\{\left\langle u^{*}, u\right\rangle-g(u): u \in W\right\}, \forall u^{*} \in W^{*}$.

Definition 2.2 ([5], Definition 2.2). The function $g: W \rightarrow(-\infty,+\infty]$ is called Legendre if

(L1) $\operatorname{int}(\operatorname{dom} g) \neq \varnothing, g$ is Gâteaux differentiable on $\operatorname{int}(\operatorname{dom} g)$ and $\operatorname{dom}(\nabla g)=\operatorname{int}(\operatorname{dom} g)$.

(L2) $\operatorname{int}\left(\operatorname{dom} g^{*}\right) \neq \varnothing, g^{*}$ is Gâteaux differentiable on $\operatorname{int}\left(\operatorname{dom} g^{*}\right)$ and $\operatorname{dom}\left(\nabla g^{*}\right)=\operatorname{int}\left(\operatorname{dom} g^{*}\right)$.

Remark 2.3 ([5], Remark 2.3). Assume that $g: W \rightarrow(-\infty,+\infty]$ is a Legendre function. Then

(1) $g$ is Legendre if and only if $g^{*}$ is Legendre.

(2) $\nabla g=\left(\nabla g^{*}\right)^{-1}, \operatorname{ran}(\nabla g)=\operatorname{dom}\left(\nabla g^{*}\right)$ and $\operatorname{ran}\left(\nabla g^{*}\right)=\operatorname{dom}(\nabla g)=\operatorname{int}(\operatorname{dom} g)$, where $\operatorname{ran}(\nabla g)$ is the range of $\nabla g$.

Definition 2.4 ([4], p.324). Let $g: W \rightarrow(-\infty,+\infty]$ be Gâteaux differentiable. Then, the function $D_{g}: \operatorname{dom} g \times \operatorname{int}(\operatorname{dom} g) \rightarrow[0, \infty)$, defined by $D_{g}(u, v)=g(u)-g(v)-\langle\nabla g(v), u-v\rangle$ is called the Bregman distance with respect to $g$.

From the definition, for all $u \in \operatorname{dom} g$ and $v, w \in \operatorname{int}(\operatorname{dom} g)$, we have

$$
D_{g}(u, v)+D_{g}(v, w)-D_{g}(u, w)=\langle\nabla g(w)-\nabla g(v), u-v\rangle \text {. }
$$

Let $g: W \rightarrow(-\infty,+\infty]$ be Gâteaux differentiable and $V_{g}: W \times W^{*} \rightarrow[0, \infty)$ be defined by

$$
V_{g}\left(u, u^{*}\right)=g(u)-\left\langle u^{*}, u\right\rangle+g^{*}\left(u^{*}\right) \text { for all } u \in W \text { and } u^{*} \in W^{*} .
$$

Remark 2.5 Let $g: W \rightarrow(-\infty,+\infty]$ be a Gâteaux differentiable function. Then

(1) ([9], Lemma 3.2) For any $u \in W$ and $u^{*} \in W^{*}$, we have $V_{g}\left(u, u^{*}\right)=D_{g}\left(u, \nabla g^{*}\left(u^{*}\right)\right)$.

(2) ([10], p.7]) $V_{g}$ is convex in the second variable. In addition, for any $u \in \operatorname{dom} g$, $\left\{u_{k}\right\}_{k=1}^{m} \subset \operatorname{int}(\operatorname{dom} g)$ and $\left\{t_{k}\right\}_{k=1}^{m} \subset[0,1]$ with $\sum_{k=1}^{m} t_{k}=1$, we have $D_{g}\left(u, \nabla g^{*}\left(\sum_{k=1}^{m} t_{k} \nabla g\left(u_{k}\right)\right)\right) \leq \sum_{k=1}^{m} t_{k} D_{g}\left(u, u_{k}\right)$. 
Definition 2.6 ([2], p.69). Let $g: W \rightarrow(-\infty,+\infty]$ be Legendre and $\Omega$ be a nonempty, convex and closed subset of $\operatorname{int}(\operatorname{dom} g)$. The Bregman projection of $u \in \operatorname{int}(\operatorname{dom} g)$ onto $\Omega$ is the unique vector $P_{\Omega}^{g}(u) \in \Omega$ statisfying $D_{g}\left(P_{\Omega}^{g}(u), u\right)=\inf \left\{D_{g}(v, u): v \in \Omega\right\}$.

Remark 2.7 ([8], Remark 2.1). (1) If $W$ is a uniformly smooth, strictly convex Banach space and $g(u)=\|u\|^{2}$ for all $u \in W$, then $\nabla g(u)=2 J u$ for all $u \in W$ and $J$ is the normalized duality mapping which is defined by $J u=\left\{u^{*} \in W^{*}:\left\langle u, u^{*}\right\rangle=\|u\|^{2}=\left\|u^{*}\right\|^{2}\right\}$ for all $u \in W$. Then the Bregman distance $D_{g}(u, v)$ is reduced into the Lyapunov function $\phi(u, v)$ which is defined by $\phi(u, v)=\|u\|^{2}-2\langle u, J v\rangle+\|v\|^{2}$ for all $u, v \in W$. Therefore, the Bregman projection $P_{\Omega}^{g}(u)$ is reduced into the generalized projection $\prod_{\Omega}(u)$ in a smooth space which is defined by $\phi\left(\prod_{\Omega}(u), u\right)=\min \{\phi(v, u): v \in \Omega\}$.

(2) If $W$ is a Hilbert space and $g(u)=\|u\|^{2}$ for all $u \in W$, then $D_{g}(u, v)=\|u-v\|^{2}$ for all $u, v \in W$ and $J$ is the identity mapping. Therefore, the Bregman projection $P_{\Omega}^{g}(u)$ is reduced into the metric projection from $W$ onto $\Omega$.

Definition 2.8 ([15], p.1). Let $g: W \rightarrow(-\infty,+\infty]$ be Gâteaux differentiable. Then

(1) $g$ is called totally convex at $u \in \operatorname{int}(\operatorname{dom} g)$ if any $\varepsilon>0$, we have

$v_{g}(u, \varepsilon)=\inf \left\{D_{g}(v, u): y \in \operatorname{dom} g,\|v-u\|=\varepsilon\right\}>0$.

(2) $g$ is called totally convex if $g$ is totally convex at every point $u \in \operatorname{int}(\operatorname{dom} f)$.

(3) $g$ is called totally convex on bounded subsets of $W$ if any nonempty bounded subset $E$ of $W$ and $t>0$, we have $v_{g}(E, \varepsilon)=\inf \left\{v_{g}(u, \varepsilon): u \in E \cap \operatorname{dom} g\right\}>0$.

Proposition 2.9 ([15], Proposition 2.2). Let $g: W \rightarrow(-\infty,+\infty]$ be Gâteaux differentiable. Then $g$ is totally convex at $u \in \operatorname{int}(\operatorname{dom} g)$ if and only if for any sequense $\left\{v_{n}\right\} \subset \operatorname{int}(\operatorname{dom} g)$ such that $\lim _{n \rightarrow \infty} D_{g}\left(v_{n}, u\right)=0$, we have $\lim _{n \rightarrow \infty}\left\|v_{n}-u\right\|=0$.

Proposition 2.10 ([2], Lemma 2.1.2). Let $g: W \rightarrow(-\infty,+\infty]$ be Gâteaux differentiable. Then $g$ is totally convex on bounded sets if and only if for any sequence $\left\{u_{n}\right\} \subset \operatorname{dom} g$ and $\left\{v_{n}\right\} \subset \operatorname{int}(\operatorname{dom} g)$ such that $\left\{u_{n}\right\}$ is bounded and $\lim _{n \rightarrow \infty} D_{g}\left(v_{n}, u_{n}\right)=0$, we have $\lim _{n \rightarrow \infty}\left\|v_{n}-u_{n}\right\|=0$.

Proposition 2.11 ([3], Corollary 4.4). Let $g: W \rightarrow(-\infty,+\infty]$ be Gâteaux differentiable and totally convex on $\operatorname{int}(\operatorname{dom} g), \Omega$ be a nonempty, closed and convex subset and $u \in \operatorname{int}(\operatorname{dom} g)$. Then

(1) $w=P_{\Omega}^{g}(u)$. if and only if $\langle\nabla g(u)-\nabla g(w), w-v\rangle \geq 0, v \in \Omega$.

(2) $D_{g}\left(v, P_{\Omega}^{g}(u)\right)+D_{g}\left(P_{\Omega}^{g}(u), u\right) \leq D_{g}(v, u), v \in \Omega$.

Proposition 2.12 ([13] Lemma 1). If $g: W \rightarrow \mathbb{R}$ is Gâteaux differentiable and totally convex on $W, u \in W$ and $\left\{u_{n}\right\} \subset W$ satisfying $\left\{D_{g}\left(u_{n}, u\right)\right\}$ is bounded, then the sequence $\left\{u_{n}\right\}$ is bounded.

Proposition 2.13 ([16], Proposition 2.3). If $g$ is Legendre such that $\nabla g^{*}$ is bounded on bounded subsets, $u \in W$ and $\left\{u_{n}\right\} \subset W$ satisfying $\left\{D_{g}\left(u, u_{n}\right)\right\}$ is bounded, then the sequence $\left\{u_{n}\right\}$ is bounded.

Definition 2.14 ([17],_p.203, p.207, p.221). Let $S_{1}=\{u \in W:\|u\|<1\}$ and $B_{\varepsilon}=\{u \in W:\|u\| \leq \varepsilon\}$ for some $\varepsilon>0$. Then 
(1) $g: W \rightarrow \mathbb{R}$ is called uniformly convex on bounded subsets if $\rho_{\varepsilon}(\lambda)>0$ for all $\lambda, \varepsilon>0$, where $\rho_{\varepsilon}:[0, \infty) \rightarrow[0, \infty)$ is defined by $\rho_{\varepsilon}(\lambda)=\inf _{\left.u, v \in B_{\varepsilon},\|u-v\|=\lambda \delta \notin 0,1\right)} \frac{\delta g(u)+(1-\delta) g(v)-g(\delta u+(1-\delta) v)}{\delta(1-\delta)}$.

(2) $g: W \rightarrow \mathbb{R}$ is called uniformly smooth on bounded subsets if $\lim _{\lambda \rightarrow 0} \frac{\sigma_{\varepsilon}(\lambda)}{\lambda}=0$ for all $\varepsilon>0$, where $\sigma_{\varepsilon}:[0, \infty) \rightarrow[0, \infty)$ is defined by $\sigma_{\varepsilon}(\lambda)=\sup _{u \in B_{\varepsilon}, v \in S_{1}, \delta \in(0,1)} \frac{\delta g(u+(1-\delta) \lambda v)+(1-\delta) g(u-\delta \lambda v)-g(u)}{\delta(1-\delta)}$.

Remark 2.15 ([11], p.7). The function $g$ is uniformly convex on bounded subsets if and only if $g$ is totally convex on bounded subsets.

Definition 2.16 ([9], p.509). The function $g: W \rightarrow(-\infty,+\infty]$ is called strongly coercive if $\lim _{\|u\| \rightarrow+\infty} \frac{g(u)}{\|u\|}=+\infty$.

Proposition 2.17 ([17], Proposition 3.6.3). Let $g: W \rightarrow \mathbb{R}$ be strongly coercive, continuous and convex. Then $g$ is bounded on bounded subsets and uniformly smooth on bounded subsets if and only if $\operatorname{dom}\left(g^{*}\right)=W^{*}, g^{*}$ is strongly coercive and uniformly convex on bounded subsets.

Proposition 2.18 ([17], Proposition 3.6.4). Let $g: W \rightarrow \mathbb{R}$ be convex, continuous and bounded on bounded subsets of $W$. Then the following statements are equivalent.

(1) $g$ is uniformly convex on bounded subsets and strongly coercive.

(2) $\operatorname{Dom}\left(g^{*}\right)=W^{*}, g^{*}$ is bounded and uniformly smooth on bounded subsets.

(3) $\operatorname{Dom}\left(g^{*}\right)=W^{*}, g^{*}$ is Fréchet differentiable and $\nabla g^{*}$ is uniformly continuous on bounded subsets.

Lemma 2.19 ([11], Lemma 2.2). Let $r>0$ and $g: W \rightarrow \mathbb{R}$ be convex and uniformly convex on bounded subsets. Then $g\left(\sum_{n=1}^{m} a_{n} u_{n}\right) \leq \sum_{n=1}^{m} a g\left(u_{n}\right)-a_{i} a_{j} \rho_{\varepsilon}\left(\left\|u_{i}-u_{j}\right\|\right) \quad$ with $\quad i, j \in\{1,2, \ldots, m\}$, $u_{n} \in B_{\varepsilon}=\{u \in W:\|u\| \leq \varepsilon\}$ and $a_{n} \in[0,1]$ such that $\sum_{n=1}^{m} a_{n}=1$, and the function $\rho_{\varepsilon}$ is defined as in Definition 2.13.

We denote by $F(S)=\{w \in \Omega: S w=w\}$ the set of fixed points of $S: \Omega \rightarrow \Omega$.

Definition 2.20 ([5], Definition 2.10). Let $S: \Omega \rightarrow \Omega$ be a mapping, $D_{g}$ be the Bregman distance, $\phi$ be the Lyapunov function. Then

(1) $S$ is called a Bregman quasi-asymptotically nonexpansive mapping if $F(S) \neq \varnothing$ and there exists a real sequence $\left\{\delta_{n}\right\} \subset[1, \infty)$ with $\lim _{n \rightarrow \infty} \delta_{n}=1$ such that $D_{g}\left(u, S^{n} v\right) \leq \delta_{n} D_{g}(u, v)$ for all $v \in \Omega$ and $u \in F(S)$.

(2) $S$ is called a Bregman totally quasi-asymptotically nonexpansive mapping if $F(S) \neq \varnothing$ and there exist nonnegative real sequences $\left\{\alpha_{n}\right\},\left\{\beta_{n}\right\}$ with $\lim _{n \rightarrow \infty} \alpha_{n}=\lim _{n \rightarrow \infty} \beta_{n}=0$ and a strictly increasing continuous function $\zeta: \mathbb{R}^{+} \rightarrow \mathbb{R}^{+}$with $\zeta(0)=0$ such that for all $v \in \Omega$ and $u \in F(S)$, we have $D_{g}\left(u, S^{n} v\right) \leq D_{g}(u, v)+\alpha_{n} \zeta\left(D_{g}(u, v)\right)+\beta_{n}$. 
(3) $S$ is called a Bregman firmly nonexpansive mapping if for all $u, v \in \Omega$, we have

$\langle\nabla g(S u)-\nabla g(S v), S u-S v\rangle \leq\langle\nabla g(u)-\nabla g(v), S u-S v\rangle$. (4) $S$ is called a Bregman quasi-nonexpansive mapping if $F(S) \neq \varnothing$ and for all $u \in \Omega$ and $v \in F(S)$, we have $D_{g}(u, S v) \leq D_{g}(u, v)$.

(5) $S$ is called a totally quasi- $\phi$-asymptotically nonexpansive mapping if $F(S) \neq \varnothing$ and there exist nonnegative real sequences $\left\{\alpha_{n}\right\},\left\{\beta_{n}\right\}$ with $\lim _{n \rightarrow \infty} \alpha_{n}=\lim _{n \rightarrow \infty} \beta_{n}=0$ and a strictly increasing continuous function $\zeta: \mathbb{R}^{+} \rightarrow \mathbb{R}^{+}$with $\zeta(0)=0$ such that for all $v \in \Omega$ and $u \in F(S)$, we have $\phi\left(u, S^{n} v\right) \leq \phi(u, v)+\alpha_{n} \zeta\left(\phi_{g}(u, v)\right)+\beta_{n}$.

(6) $S$ is called a totally quasi- $\phi$-asymptotically nonexpansive mapping if $F(S) \neq \varnothing$ and there exists a real sequence $\left\{\delta_{n}\right\} \subset[1, \infty)$ with $\lim _{n \rightarrow \infty} \delta_{n}=1$ such that $\phi\left(u, S^{n} v\right) \leq \delta_{n} \phi(u, v)$ for all $v \in \Omega$ and $u \in F(S)$.

Remark 2.21 ([5], p.42). (1) If $S$ is a Bregman quasi-asymptotically nonexpansive mapping, then $S$ is a Bregman totally quasi-asymptotically nonexpansive mapping with $\zeta(\lambda)=\lambda$ for all $\lambda \geq 0$, $\alpha_{n}=\delta_{n}-1$ with $\delta_{n} \geq 1$ satisfying $\lim _{n \rightarrow \infty} \delta_{n}=1$ and $\beta_{n}=0 ;$ but the converse is not true.

(2) If $S$ is a quasi- $\phi$-asymptotically nonexpansive mapping, then $S$ is a totally quasi- $\phi$ asymptotically nonexpansive mapping with $\zeta(\lambda)=\lambda$ for all $\lambda \geq 0, \alpha_{n}=\delta_{n}-1$ with $\delta_{n} \geq 1$ satisfying $\lim _{n \rightarrow \infty} \delta_{n}=1$ and $\beta_{n}=0$.

(3) If $S$ is a Bregman firmly nonexpansive mapping, then $S$ is a Bregman quasi-nonexpansive mapping.

Definition 2.22 ([18], Definition 2.10). Let $S: \Omega \rightarrow \Omega$ be a mapping. Then

(1) $S$ is called closed if any sequence $\left\{u_{n}\right\}$ in $\Omega$ such that $\lim _{n \rightarrow \infty} u_{n}=u \in \Omega$ and $\lim _{n \rightarrow \infty} S u_{n}=v \in \Omega$, we have $S u=v$.

(2) $S$ is called uniformly asymptotically regular on $\Omega$ if for all bounded subset $U$ of $\Omega$ we have $\limsup _{n \rightarrow \infty}\left\|S^{n+1} u-S^{n} u\right\|=0$.

Lemma 2.23 ([5], Lemma 2.16). Suppose that $g: W \rightarrow(-\infty,+\infty]$ is a Legendre, totally convex on bounded subsets of $W$, and $S: \Omega \rightarrow \Omega$ is a closed and Bregman totally quasi-asymptotically nonexpansive mapping. Then $F(S)$ is convex and closed.

In order to slove (GMEP), we suppose that $f, \varphi, \psi$ satisfy the following conditions.

(C1) $f(u, u)=0, \forall u \in \Omega$.

(C2) $f(u, v)+f(v, u) \leq 0, \forall u, v \in \Omega$.

$\left(\mathrm{C} 3 \limsup _{\lambda \rightarrow 0} f(\lambda w+(1-\lambda) u, v) \leq f(u, v), \forall u, v, w \in \Omega\right.$

(C4) For each $u \in \Omega, v \mapsto f(u, v)$ is convex and lower semi-continuous.

(C5) $\varphi: \Omega \rightarrow \mathbb{R}$ is convex and lower semi-continuous.

(C6) $\psi: \Omega \rightarrow X^{*}$ is continuous monotone.

Lemma 2.24 ([6], Lemma 2.8). Assume that $g: W \rightarrow \mathbb{R}$ is a Legendre and strongly coercive function, the functions $f, \varphi, \psi$ satisfy the conditions (C1)-(C6). Consider the mapping $\operatorname{Res}_{f, \varphi, \psi}^{g}: W \rightarrow 2^{\Omega}$ which is defined by

$$
\operatorname{Res}_{f, \varphi, \psi}^{g}(u)=\{w \in \Omega: f(w, v)+\varphi(v)+\langle\psi(w), v-w\rangle+\langle\nabla g(w)-\nabla g(u), v-w\rangle \geq \varphi(w), \forall v \in \Omega\} .
$$

Then 
(1) $\operatorname{Dom}\left(\operatorname{Res}_{f, \varphi, \psi}^{g}\right)=W, \operatorname{Res}_{f, \varphi, \psi}^{g}$ is a single-valued and Bregman firmly nonexpansive mapping.

(2) $F\left(\operatorname{Res}_{f, \varphi, \psi}^{g}\right)=G M E P(f, \varphi, \psi)$, and $\operatorname{GMEP}(f, \varphi, \psi)$ is convex and closed.

(3) For all $u \in W$ and $v \in F\left(\operatorname{Res}_{f, \varphi, \psi}^{g}\right)$, we have $D_{g}\left(v, \operatorname{Res}_{f, \varphi, \psi}^{g}(u)\right)+D_{g}\left(\operatorname{Res}_{f, \varphi, \psi}^{g}(u), u\right) \leq D_{g}(v, u)$.

\section{Main results}

Let $W$ be a real reflexive Banach space and $\Omega$ be a nonempty, closed and convex subset of $W$. We denote by $I=\{1,2, \ldots, N\}$ with $N \in \mathbb{N}$. Suppose that for each $i \in I, \quad S_{i}: \Omega \rightarrow \Omega$ is Bregman totally quasiasymptotically nonexpansive mapping with nonnegative real sequences $\left\{\alpha_{n}^{(i)}\right\}$ and $\left\{\beta_{n}^{(i)}\right\}$ satisfying $\lim _{n \rightarrow \infty} \alpha_{n}^{(i)}=\lim _{n \rightarrow \infty} \beta_{n}^{(i)}=0$ and strictly increasing continuous functions $\zeta^{(i)}:[0, \infty) \rightarrow[0, \infty)$ with $\zeta^{(i)}(0)=0$. Put $\alpha_{n}=\max \left\{\alpha_{n}^{(i)}: i \in I\right\}, \quad \beta_{n}=\max \left\{\beta_{n}^{(i)}: i \in I\right\} \quad$ and $\zeta(t)=\max \left\{\zeta^{(i)}(t): i \in I\right\} \quad$ for all $t \geq 0$. Then $\lim _{n \rightarrow \infty} \alpha_{n}=\lim _{n \rightarrow \infty} \beta_{n}=0, \zeta(0)=0$ and $D_{g}\left(p, S_{i}^{n} u\right) \leq D_{g}(p, u)+\alpha_{n} \zeta\left(D_{g}(p, u)\right)+\beta_{n}$ for all $u \in \Omega, p \in \bigcap_{i \in I} F\left(S_{i}\right)$ and for all $i \in I$.

Theorem 3.1. Assume that $W$ is a real reflexive Banach space, and $\Omega$ is a nonempty, closed and convex subset of $W$. Let $g: W \rightarrow \mathbb{R}$ be Legendre, strongly coercive on $W$, and bounded, totally convex, uniformly Fréchet differentiable on bounded subsets of $W$. For each $k \in K:=\{1,2, \ldots, M\}$ with $M \in \mathbb{N}$, the functions $f_{k}, \varphi_{k}, \psi_{k}$ satisfy the conditions (C1)-(C6). For each $i \in I, \quad S_{i}: \Omega \rightarrow \Omega$ is a closed, uniformly asymptotically regular and Bregman totally quasi-asymptotically nonexpansive mapping with nonnegative real sequences $\left\{\alpha_{n}^{(i)}\right\}$ and $\left\{\beta_{n}^{(i)}\right\}$ satisfying $\lim _{n \rightarrow \infty} \alpha_{n}^{(i)}=\lim _{n \rightarrow \infty} \beta_{n}^{(i)}=0$ and strictly increasing continuous function $\zeta^{(i)}:[0, \infty) \rightarrow[0, \infty)$ with $\zeta^{(i)}(0)=0$ such that

$$
\mathcal{F}=\left(\bigcap_{i \in I} F\left(S_{i}\right)\right) \cap\left(\bigcap_{k \in K} \operatorname{GMEP}\left(f_{k}, \varphi_{k}, \psi_{k}\right)\right)
$$

is nonempty and bounded. Let $\left\{u_{n}\right\}$ be a sequence generated by

$$
\left\{\begin{array}{l}
u_{1}, v_{1} \in \Omega, \Omega_{1}=\Omega \\
w_{n}^{(i)}=\nabla g^{*}\left[a_{n} \nabla g\left(v_{n}\right)+\left(1-a_{n}\right) \nabla g\left(S_{i}^{n} u_{n}\right)\right] \\
i_{n}=\arg \max \left\{D_{g}\left(u_{n}, w_{n}^{(i)}\right): i \in I\right\}, \bar{w}_{n}=w_{n}^{\left(i_{n}\right)} \\
v_{n+1}=H^{M}\left(\bar{w}_{n}\right) \\
\Omega_{n+1}=\left\{u \in \Omega_{n}: D_{g}\left(u, v_{n+1}\right) \leq a_{n} D_{g}\left(u, v_{n}\right)+\left(1-a_{n}\right) D_{g}\left(u, u_{n}\right)+\xi_{n}\right\} \\
u_{n+1}=P_{\Omega_{n+1}}^{g}\left(u_{1}\right), \forall n \geq 2
\end{array}\right.
$$

where $\xi_{n}=\left(1-a_{n}\right)\left[\alpha_{n} \sup \left\{\zeta\left(D_{g}\left(u, u_{n}\right)\right): u \in \mathcal{F}\right\}+\beta_{n}\right]$, the function $R_{k}:=\operatorname{Res}_{f_{k}, \varphi_{k}, \psi_{k}}^{g}$ is defined as in Lemma 2.24, $H^{k}=R_{k}\left(R_{k-1}\left(R_{k-2}\left(\ldots\left(R_{1}\right)\right)\right)\right)$ for all $k \in K,\left\{a_{n}\right\} \subset[0,1]$ such that $\lim _{n \rightarrow \infty} a_{n}=0$. Then the sequence $\left\{u_{n}\right\}$ strongly converges to $p=P_{\mathcal{F}}^{g}\left(u_{1}\right)$.

Proof. We divide the proof of this theorem into six steps.

Step 1. We claim that $P_{\mathcal{F}}^{g}\left(u_{1}\right)$ is well-defined. Indeed, by Lemma 2.23 and Lemma 2.24, we find that $F\left(S_{i}\right)$ and $\operatorname{GMEP}\left(f_{k}, \varphi_{k}, \psi_{k}\right)$ are closed and convex for all $i \in I$ and $k \in K$. Therefore, by combining this 
with the assumption, we obtain that $\mathcal{F}=\left(\bigcap_{i \in I} F\left(S_{i}\right)\right) \cap\left(\bigcap_{k \in K} \operatorname{GMEP}\left(f_{k}, \psi_{k}, \varphi_{k}\right)\right)$ is a nonempty, closed and convex subset of $\Omega$. This fact ensures that $P_{\mathcal{F}}^{g}\left(u_{1}\right)$ is well-defined.

Step 2. We claim that $P_{\Omega_{n+1}}^{g}\left(u_{1}\right)$ is well-defined. We first claim that $\Omega_{n}$ is convex and closed for all $n \geq 1$ by mathematical induction. Obviously, for $n=1$, we have $\Omega_{1}=\Omega$ is closed and convex. Now we suppose that $\Omega_{m}$ is convex and closed for some $m \geq 1$. Then, by the definition of $\Omega_{m+1}$, we have

$$
\begin{aligned}
\Omega_{m+1} & =\left\{u \in \Omega_{m}: a_{m}\left\langle\nabla g\left(v_{m}\right), u-v_{m}\right\rangle+\left(1-a_{m}\right)\left\langle\nabla g\left(u_{m}\right), u-u_{m}\right\rangle-\left\langle\nabla g\left(v_{m+1}\right), u-v_{m+1}\right\rangle\right. \\
& \left.\leq g\left(v_{m+1}\right)-a_{m} g\left(v_{m}\right)-\left(1-a_{m}\right) g\left(u_{m}\right)+\xi_{m}\right\} .
\end{aligned}
$$

By combining (3.2) with the continuity of $\nabla g($.$) , we get that \Omega_{m+1}$ is convex and closed. Therefore, $\Omega_{n}$ is convex and closed for all $n \geq 1$.

Next, we will prove that $\mathcal{F} \subset \Omega_{n}$ for all $n \geq 1$ by mathematical induction. Obviously, we have $\mathcal{F} \subset \Omega=\Omega_{1}$. Now, we suppose that $\mathcal{F} \subset \Omega_{m}$ for some $m \geq 1$. We show that $\mathcal{F} \subset \Omega_{m+1}$. Indeed, for any $u \in \mathcal{F}$, we get $u \in \Omega_{m}$. By Remark 2.21.(2) and Lemma 2.24, we find that $H^{M}$ is a Bregman quasinonexpansive mapping. Then

$$
D_{g}\left(u, v_{m+1}\right)=D_{g}\left(u, H^{M}\left(\bar{w}_{m}\right)\right) \leq D_{g}\left(u, \bar{w}_{m}\right) .
$$

Furthermore, by Remark 2.5.(2) and the fact that $S_{i}$ is a Bregman totally quasi-asymptotically nonexpansive mapping, we obtain

$$
\begin{aligned}
& D_{g}\left(u, \bar{w}_{m}\right)=D_{g}\left(u, w_{m}^{\left(i_{m}\right)}\right) \\
& =D_{g}\left(u, \nabla g^{*}\left[a_{m} \nabla g\left(v_{m}\right)+\left(1-a_{m}\right) \nabla g\left(S_{i}^{m} u_{m}\right)\right]\right) \\
& \leq a_{m} D_{g}\left(u, v_{m}\right)+\left(1-a_{m}\right) D_{g}\left(u, S_{i}^{m} u_{m}\right) \\
& \leq a_{m} D_{g}\left(u, v_{m}\right)+\left(1-a_{m}\right)\left[D_{g}\left(u, u_{m}\right)+\alpha_{m} \zeta\left(D_{g}\left(u, u_{m}\right)\right)+\beta_{n}\right] \\
& \quad=a_{m} D_{g}\left(u, v_{m}\right)+\left(1-a_{m}\right) D_{g}\left(u, u_{m}\right)+\xi_{m} .
\end{aligned}
$$

It follows from (3.3) and (3.4) that

$$
D_{g}\left(u, v_{m+1}\right) \leq a_{m} D_{g}\left(u, v_{m}\right)+\left(1-a_{m}\right) D_{g}\left(u, u_{m}\right)+\xi_{m} \text {. }
$$

This leads to $u \in \Omega_{m+1}$ and hence $\mathcal{F} \subset \Omega_{m+1}$. Therefore, $\mathcal{F} \subset \Omega_{n}$ for all $n \geq 1$. By combining this with $\mathcal{F} \neq \varnothing$, we have $\Omega_{n} \neq \varnothing$. By the above, we find that $\Omega_{n+1}$ is nonempty, closed and convex. This proves that $P_{\Omega_{n+1}}^{g}\left(u_{1}\right)$ is well-defined.

Step 3. We claim that $\left\{u_{n}\right\}$ and $\left\{v_{n}\right\}$ are bounded, and the limit $\lim _{n \rightarrow \infty} D_{g}\left(u_{n}, u_{1}\right)$ exists. Indeed, it follows $u_{n}=P_{\Omega_{n}}^{g}\left(u_{1}\right)$ and Proposition 2.11 that

$$
D_{g}\left(y, u_{n}\right)+D_{g}\left(u_{n}, u_{1}\right) \leq D_{g}\left(y, u_{1}\right)
$$

for all $y \in \Omega_{n}$. Let $u \in \mathcal{F}$. Since $\mathcal{F} \subset \Omega_{n}$, we get $u \in \Omega_{n}$. By choosing $y=u$ in (3.6), we obtain

$$
D_{g}\left(u, u_{n}\right)+D_{g}\left(u_{n}, u_{1}\right) \leq D_{g}\left(u, u_{1}\right) .
$$

This implies that $D_{g}\left(u_{n}, u_{1}\right) \leq D_{g}\left(u, u_{1}\right)-D_{g}\left(u, u_{n}\right) \leq D_{g}\left(u, u_{1}\right)$. Therefore, $\left\{D_{g}\left(u_{n}, u_{1}\right)\right\}$ is bounded. Then, from Proposition 2.12, we find that the sequence $\left\{u_{n}\right\}$ is bounded. Furthermore, by (3.7), we 
have $D_{g}\left(u, u_{n}\right) \leq D_{g}\left(u, u_{1}\right)-D_{g}\left(u_{n}, u_{1}\right) \leq D_{g}\left(u, u_{1}\right)$. This proves that $\left\{D_{g}\left(u, u_{n}\right)\right\}$ is bounded. By combining this with the boundedness of $\left\{\alpha_{n}\right\}$ and $\left\{\beta_{n}\right\}$, we find that there exists $b>0$ such that

$$
b=\sup _{n \in \mathbb{N}^{*}}\left\{\alpha_{n} \sup \left\{\zeta\left(D_{g}\left(u, u_{n}\right)\right): u \in \mathcal{F}\right\}+\beta_{n}\right\} .
$$

Put $a=\max \left\{D_{g}\left(u, v_{1}\right), \sup _{n \in \mathbb{N}^{*}} D_{g}\left(u, u_{n}\right)\right\}$. We will claim that $D_{g}\left(u, v_{n}\right) \leq a+b$ for all $n \geq 1$ by mathematical induction. Indeed, we have $D_{g}\left(u, v_{1}\right) \leq a \leq a+b$. Now, we suppose that $D_{g}\left(u, v_{m}\right) \leq a+b$ for some $m \geq 1$. Then, by (3.5), we have

$$
\begin{aligned}
D_{g}\left(u, v_{m+1}\right) & \leq a_{m} D_{g}\left(u, v_{m}\right)+\left(1-a_{m}\right) D_{g}\left(u, u_{m}\right)+\left(1-a_{m}\right) b \\
& \leq a_{m}(a+b)+\left(1-a_{m}\right) a+\left(1-a_{m}\right) b=a+b .
\end{aligned}
$$

This imples that $D_{g}\left(u, v_{n}\right) \leq a+b$ for all $n \geq 1$ and hence the sequence $\left\{D_{g}\left(u, v_{n}\right)\right\}$ is bounded. Furthermore, by Proposition 2.18, we find that $g^{*}$ is bounded on bounded subsets. By Remark 2.1(1), we conclude that $\nabla g^{*}$ is bounded on bounded subsets. It follows from Proposition 2.13 and the boundedness of $\left\{D_{g}\left(u, v_{n}\right)\right\}$ that $\left\{v_{n}\right\}$ is bounded.

Moreover, we have $u_{n+1}=P_{\Omega_{n+1}}^{g}\left(u_{1}\right) \in \Omega_{n+1} \subset \Omega_{n}$. By choosing $y=u_{n+1}$ in (3.6), we get

$D_{g}\left(u_{n+1}, u_{n}\right)+D_{g}\left(u_{n}, u_{1}\right) \leq D_{g}\left(u_{n+1}, u_{1}\right)$.

This implies that $D_{g}\left(u_{n}, u_{1}\right) \leq D_{g}\left(u_{n+1}, u_{1}\right)-D_{g}\left(u_{n+1}, u_{n}\right) \leq D_{g}\left(u_{n+1}, u_{1}\right)$. This proves that $\left\{D_{g}\left(u_{n}, u_{1}\right)\right\}$ is a nondecreasing sequence. By combining this with the boundedness of the sequence $\left\{D_{g}\left(u_{n}, u_{1}\right)\right\}$, we conclude that the $\operatorname{limit}_{n \rightarrow \infty} \lim _{g}\left(u_{n}, u_{1}\right)$ exsits.

Step 4. We claim that $\lim _{n \rightarrow \infty} u_{n}=p \in \Omega$. Indeed, for $m>n$, we get that $u_{m}=P_{\Omega_{m}}^{g}\left(u_{1}\right) \in \Omega_{m} \subset \Omega_{n}$. By choosing $y=u_{m}$ in (3.6), we get $D_{g}\left(u_{m}, u_{n}\right)+D_{g}\left(u_{n}, u_{1}\right) \leq D_{g}\left(u_{m}, u_{1}\right)$. This leads to

$$
0 \leq D_{g}\left(u_{m}, u_{n}\right) \leq D_{g}\left(u_{m}, u_{1}\right)-D_{g}\left(u_{n}, u_{1}\right) .
$$

Taking the limit (3.8) as $m, n \rightarrow \infty$ and using the existence of $\lim _{n \rightarrow \infty} D_{g}\left(u_{n}, u_{1}\right)$, we obtain

$$
\lim _{m, n \rightarrow \infty} D_{g}\left(u_{m}, u_{n}\right)=0 \text {. }
$$

It follows from (3.9), the boundedness of the sequence $\left\{u_{n}\right\}$, and Proposition 2.10 we have

$$
\lim _{m, n \rightarrow \infty}\left\|u_{m}-u_{n}\right\|=0
$$

This proves that $\left\{u_{n}\right\}$ is a Cauchy sequence in $\Omega$. Since $W$ is a Banach space and $\Omega$ is a closed subset of $W$, there exists $p \in \Omega$ such that $\lim _{n \rightarrow \infty} u_{n}=p$.

Step 5. We claim that $p \in \mathcal{F}$. First, we prove that $p \in \bigcap_{i \in I} F\left(S_{i}\right)$. Indeed, by choosing $m=n+1$ in (3.9) and (3.10), we obtain

$$
\lim _{n \rightarrow \infty} D_{g}\left(u_{n+1}, u_{n}\right)=\lim _{n \rightarrow \infty}\left\|u_{n+1}-u_{n}\right\|=0 .
$$

Since $u_{n+1}=P_{\Omega_{n+1}}^{g}\left(u_{1}\right) \in \Omega_{n+1} \subset \Omega_{n}$, we get

$$
D_{g}\left(u_{n+1}, v_{n+1}\right) \leq a_{n} D_{g}\left(u_{n+1}, v_{n}\right)+\left(1-a_{n}\right) D_{g}\left(u_{n+1}, u_{n}\right)+\xi_{n} .
$$


Let $u \in \mathcal{F}$. By the boundedness of $\left\{D_{g}\left(u, u_{n}\right)\right\}$ and $\lim _{n \rightarrow \infty} \alpha_{n}=\lim _{n \rightarrow \infty} \beta_{n}=0$, we find that $\lim _{n \rightarrow \infty} \xi_{n}=0$. By property of the Bregman distance, we have

$$
\begin{aligned}
\left|D_{g}\left(u_{n+1}, v_{n}\right)\right|=\mid\left\langle\nabla g\left(v_{n}\right)\right. & \left.-\nabla g\left(u_{n+1}\right), u-u_{n+1}\right\rangle+D_{g}\left(u, v_{n}\right)-D_{g}\left(u, u_{n+1}\right) \mid \\
& \leq\left(|| \nabla g\left(v_{n}\right)\|+\| \nabla g\left(u_{n+1}\right)||\right)\left(\|u\|+|| u_{n+1}||\right)+\left|D_{g}\left(u, v_{n}\right)\right|+\left|D_{g}\left(u, u_{n+1}\right)\right| .
\end{aligned}
$$

By Remark 2.1(3), we find that $\nabla g$ is uniformly continuous on bounded subsets. By combining this with the boundedness of $\left\{u_{n}\right\},\left\{D_{g}\left(u, u_{n}\right)\right\},\left\{D_{g}\left(u, v_{n}\right)\right\},\left\{v_{n}\right\}$ and (3.13), we find that the sequence $\left\{D_{g}\left(u_{n+1}, v_{n}\right)\right\}$ is bounded. It follows from (3.12), $\lim _{n \rightarrow \infty} a_{n}=\lim _{n \rightarrow \infty} \xi_{n}=0$, we conclude that $\lim _{n \rightarrow \infty} D_{g}\left(u_{n+1}, v_{n+1}\right)=0$. Then, by Proposition 2.10 and the boundedness of $\left\{v_{n+1}\right\}$, we find that $\lim _{n \rightarrow \infty}\left\|u_{n+1}-v_{n+1}\right\|=0$. By combining this with (3.11), we have $\lim _{n \rightarrow \infty}\left\|v_{n+1}-u_{n}\right\|=0$. Since $g$ is uniformly continuous and $\nabla g$ is uniformly continuous on bounded subsets by Remark 2.1, we find that

$$
\lim _{n \rightarrow \infty}\left\|g\left(v_{n+1}\right)-g\left(u_{n}\right)\right\|=\lim _{n \rightarrow \infty}\left\|\nabla g\left(v_{n+1}\right)-\nabla g\left(u_{n}\right)\right\|=0 .
$$

From $v_{n+1}=H^{M}\left(\bar{w}_{n}\right)$, and using Lemma 2.23(3) and (3.4), we find that

$$
\begin{aligned}
& D_{g}\left(v_{n+1}, \bar{w}_{n}\right)=D_{g}\left(H^{M}\left(\bar{w}_{n}\right), \bar{w}_{n}\right) \leq D_{g}\left(u, \bar{w}_{n}\right)-D_{g}\left(u, v_{n+1}\right) \\
& \leq a_{n} D_{g}\left(u, v_{n}\right)+\left(1-a_{n}\right) D_{g}\left(u, u_{n}\right)+\xi_{n}-D_{g}\left(u, v_{n+1}\right) \\
& \leq a_{n}\left[D_{g}\left(u, v_{n}\right)-D_{g}\left(u, u_{n}\right)\right]+\left[D_{g}\left(u, u_{n}\right)-D_{g}\left(u, v_{n+1}\right)\right]+\xi_{n} .
\end{aligned}
$$

Furthermore, by the definition of the Bregman distance, we have

$$
\begin{aligned}
& \quad\left|D_{g}\left(u, u_{n}\right)-D_{g}\left(u, v_{n+1}\right)\right| \\
& =\left|\left[g(u)-g\left(u_{n}\right)-\left\langle\nabla g\left(u_{n}\right), u-u_{n}\right\rangle\right]-\left[g(u)-g\left(v_{n+1}\right)-\left\langle\nabla g\left(v_{n+1}\right), u-v_{n+1}\right\rangle\right]\right| \\
& \quad \leq g\left(v_{n+1}\right)-g\left(u_{n}\right) \mid+\left\|\nabla g\left(v_{n+1}\right)\right\| \cdot\left\|u_{n}-v_{n+1}\right\|+\left\|\nabla g\left(v_{n+1}\right)-\nabla g\left(u_{n}\right)\right\| \cdot\left\|u-u_{n}\right\| .
\end{aligned}
$$

Then, by using (3.14), (3.16), the boundedness of $\left\{u_{n}\right\},\left\{v_{n}\right\},\left\{\nabla g\left(v_{n}\right)\right\}$ and the boundedness of $\mathcal{F}$, we have

$$
\lim _{n \rightarrow \infty}\left|D_{g}\left(u, u_{n}\right)-D_{g}\left(u, v_{n+1}\right)\right|=0 .
$$

It follows from (3.15), (3.17), the boundedness of $\left\{D_{g}\left(u, u_{n}\right)\right\},\left\{D_{g}\left(u, v_{n}\right)\right\}$ and $\lim _{n \rightarrow \infty} a_{n}=\lim _{n \rightarrow \infty} \xi_{n}=0$ that

$$
\lim _{n \rightarrow \infty} D_{g}\left(v_{n+1}, \bar{w}_{n}\right)=0 .
$$

Moreover, we conclude from (3.4) and the boundedness of $\left\{D_{g}\left(u, u_{n}\right)\right\},\left\{D_{g}\left(u, v_{n}\right)\right\}$ that $\left\{D_{g}\left(u, \bar{w}_{n}\right)\right\}$ is bounded. By combining this with the fact that $\nabla g^{*}$ is bounded on bounded subsets and using Proposition 2.13, we find that $\left\{\bar{w}_{n}\right\}$ is bounded. Then, by using Proposition 2.10 and (3.18), we obtain that

$$
\lim _{n \rightarrow \infty}\left\|v_{n+1}-\bar{w}_{n}\right\|=0 \text {. }
$$

It follows from $\lim _{n \rightarrow \infty}\left\|v_{n+1}-u_{n}\right\|=0$ and (3.19) that $\lim _{n \rightarrow \infty}\left\|u_{n}-\bar{w}_{n}\right\|=0$. By combining this with the uniform continuous of $g$, the boundedness on bounded subsets of $\nabla g$ and the inequality

$$
\left|D_{g}\left(u, \bar{w}_{n}\right)\right| \leq\left|g\left(u_{n}\right)-g\left(\bar{w}_{n}\right)\right|+\left\|\nabla g\left(\bar{w}_{n}\right)\right\| \cdot\left\|u_{n}-\bar{w}_{n}\right\|,
$$


we find that $\lim _{n \rightarrow \infty} D_{g}\left(u_{n}, \bar{w}_{n}\right)=0$. Therefore, by definition of $i_{n}$, we obtain $\lim _{n \rightarrow \infty} D_{g}\left(u_{n}, w_{n}^{(i)}\right)=0$. By using the arguments as in the proof of (3.19), we find that $\lim _{n \rightarrow \infty}\left\|u_{n}-w_{n}^{(i)}\right\|=0$. By combining this with the uniform continuous on bounded subsets of $\nabla g$, we get

$$
\lim _{n \rightarrow \infty}\left\|\nabla g\left(u_{n}\right)-\nabla g\left(w_{n}^{(i)}\right)\right\|=0 .
$$

Note that $\nabla g=\left(\nabla g^{*}\right)^{-1}$. Then we have

$$
\begin{aligned}
& \quad\left\|\nabla g\left(u_{n}\right)-\nabla g\left(w_{n}^{(i)}\right)\right\|=\left\|\nabla g\left(u_{n}\right)-a_{n} \nabla g\left(v_{n}\right)+\left(1-a_{n}\right) \nabla g\left(S_{i}^{n} u_{n}\right)\right\| \\
& =\left\|\left(1-a_{n}\right)\left[\nabla g\left(u_{n}\right)-\nabla g\left(S_{i}^{n} u_{n}\right)\right]+a_{n}\left[\nabla g\left(u_{n}\right)-\nabla g\left(v_{n}\right)\right]\right\| \\
& \\
& \geq\left(1-a_{n}\right)\left\|\nabla g\left(u_{n}\right)-\nabla g\left(S_{i}^{n} u_{n}\right)\right\|-a_{n}\left\|\nabla g\left(u_{n}\right)-\nabla g\left(v_{n}\right)\right\| .
\end{aligned}
$$

This leads to

$$
\left(1-a_{n}\right)\left\|\nabla g\left(u_{n}\right)-\nabla g\left(S_{i}^{n} u_{n}\right)\right\| \leq\left\|\nabla g\left(u_{n}\right)-\nabla g\left(w_{n}^{(i)}\right)\right\|+a_{n}\left\|\nabla g\left(u_{n}\right)-\nabla g\left(v_{n}\right)\right\| \text {. }
$$

It follows from (3.20), (3.21), the boundedness of $\left\{\nabla g\left(u_{n}\right)\right\},\left\{\nabla g\left(v_{n}\right)\right\}$ and $\lim _{n \rightarrow \infty} \alpha_{n}=0$ that

$$
\lim _{n \rightarrow \infty}\left\|\nabla g\left(u_{n}\right)-\nabla g\left(S_{i}^{n} u_{n}\right)\right\|=0 .
$$

Then we conclude from (3.22) and the uniform continuous on bounded subsets of $\nabla g^{*}$ that

$$
\lim _{n \rightarrow \infty}\left\|u_{n}-S_{i}^{n} u_{n}\right\|=0 \text {. }
$$

By combining (3.23) and $\lim _{n \rightarrow \infty} u_{n}=p$, we get that $\lim _{n \rightarrow \infty} S_{i}^{n} u_{n}=p$ for each $i \in I$. Therefore, by combining this with the uniformly asymptotically regular property of $S_{i}$ and the following inequality

$$
\left\|S_{i}^{n+1} u_{n}-p\right\| \leq\left\|S_{i}^{n+1} u_{n}-S_{i}^{n} u_{n}\right\|+\left\|S_{i}^{n} u_{n}-p\right\|
$$

we find that $\lim _{n \rightarrow \infty} S_{i}^{n+1} u_{n}=p$ and hence $\lim _{n \rightarrow \infty} S\left(S_{i}^{n} u_{n}\right)=p$. By the closedness of $S_{i}$, we have $S_{i} p=p$. It means that $p \in \bigcap_{i \in I} F\left(S_{i}\right)$.

Next, we prove that $p \in \bigcap_{k \in J} \operatorname{GMEP}\left(f_{k}, \varphi_{k}, \psi_{k}\right)$. Indeed, for each $k \in K$, by Lemma 2.24, we have

$$
\begin{aligned}
f_{k}\left(H^{k}\left(\bar{w}_{n}\right), v\right)+\varphi_{k}(v)+\left\langle\psi_{k}\left(H^{k}\left(\bar{w}_{n}\right)\right), v-H^{k}\left(\bar{w}_{n}\right)\right\rangle+\left\langle\nabla g\left(H^{k}\left(\bar{w}_{n}\right)\right)-\nabla g\left(H^{k-1}\left(\bar{w}_{n}\right)\right),\right. & \left.v-H^{k}\left(\bar{w}_{n}\right)\right\rangle \\
& \geq \varphi_{k}\left(H^{k}\left(\bar{w}_{n}\right)\right), \forall v \in \Omega .
\end{aligned}
$$

By the condition (C2), This leads to

$$
\begin{aligned}
& \varphi_{k}(v)-\varphi_{k}\left(H^{k}\left(\bar{w}_{n}\right)\right)+\left\langle\psi_{k}\left(H^{k}\left(\bar{w}_{n}\right)\right), v-H^{k}\left(\bar{w}_{n}\right)\right\rangle+\left\langle\nabla g\left(H^{k}\left(\bar{w}_{n}\right)\right)-\nabla g\left(H^{k-1}\left(\bar{w}_{n}\right)\right), v-H^{k}\left(\bar{w}_{n}\right)\right\rangle \\
& \geq-f_{k}\left(H^{k}\left(\bar{w}_{n}\right), v\right) \geq f_{k}\left(v, H^{k}\left(\bar{w}_{n}\right)\right), \forall v \in \Omega .
\end{aligned}
$$

Furthermore, by Lemma 2.24, (3.4) and the fact that $H^{k}$ is a Bregman quasi-nonexpansive mapping for each $k \in K$, we find that

$$
\begin{aligned}
& D_{g}\left(H^{k}\left(\bar{w}_{n}\right), \bar{w}_{n}\right) \leq D_{g}\left(u, H^{k-1}\left(\bar{w}_{n}\right)\right)-D_{g}\left(u, H^{k}\left(\bar{w}_{n}\right)\right) \\
& \quad \leq D_{g}\left(u, H^{k-2}\left(\bar{w}_{n}\right)\right)-D_{g}\left(u, H^{k}\left(\bar{w}_{n}\right)\right) \leq \ldots \\
& \quad \leq D_{g}\left(u, \bar{w}_{n}\right)-D_{g}\left(u, H^{k}\left(\bar{w}_{n}\right)\right) \\
& \quad \leq a_{n} D_{g}\left(u, v_{n}\right)+\left(1-a_{n}\right) D_{g}\left(u, u_{n}\right)+\xi_{n}-D_{g}\left(u, H^{k}\left(\bar{w}_{n}\right)\right) .
\end{aligned}
$$

Similarly, since $H^{M}$ is a Bregman quasi-nonexpansive mapping, we get that

$$
D_{g}\left(u, v_{n+1}\right)=D_{g}\left(u, H^{M}\left(\bar{w}_{n}\right)\right) \leq D_{g}\left(u, H^{k}\left(\bar{w}_{n}\right)\right) .
$$


It follows from (3.25) and (3.26), we have

$$
\begin{aligned}
D_{g}\left(H^{k}\left(\bar{w}_{n}\right), \bar{w}_{n}\right) & \leq a_{n} D_{g}\left(u, v_{n}\right)+\left(1-a_{n}\right) D_{g}\left(u, u_{n}\right)+\xi_{n}-D_{g}\left(u, v_{n+1}\right) \\
& =a_{n}\left[D_{g}\left(u, v_{n}\right)-D_{g}\left(u, u_{n}\right)\right]+\left[D_{g}\left(u, u_{n}\right)-D_{g}\left(u, v_{n+1}\right)\right]+\xi_{n} .
\end{aligned}
$$

By combining this with (2.17), the boundedness of $\left\{D_{g}\left(u, u_{n}\right)\right\},\left\{D_{g}\left(u, v_{n}\right)\right\}$ and $\lim _{n \rightarrow \infty} a_{n}=\lim _{n \rightarrow \infty} \xi_{n}=0$ that

$$
\lim _{n \rightarrow \infty} D_{g}\left(H^{k}\left(\bar{w}_{n}\right), \bar{w}_{n}\right)=0 .
$$

By Proposition 2.10 and the boundedness of $\left\{\bar{w}_{n}\right\}$, we find that

$$
\lim _{n \rightarrow \infty}\left\|H^{k}\left(\bar{w}_{n}\right)-\bar{w}_{n}\right\|=0 \text {. }
$$

Note that

$\left\|H^{k}\left(\bar{w}_{n}\right)-p\right\| \leq\left\|H^{k}\left(\bar{w}_{n}\right)-\bar{w}_{n}\right\|+\left\|\bar{w}_{n}-u_{n}\right\|+\left\|u_{n}-p\right\|$.

It follows from (3.28), (3.29), $\lim _{n \rightarrow \infty}\left\|u_{n}-\bar{w}_{n}\right\|=0$ and $\lim _{n \rightarrow \infty} u_{n}=p$ that $\lim _{n \rightarrow \infty} H^{k}\left(\bar{w}_{n}\right)=p$. Similarly, we find that $\lim _{n \rightarrow \infty} H^{k-1}\left(\bar{w}_{n}\right)=p$. Therefore, $\lim _{n \rightarrow \infty}\left\|H^{k}\left(\bar{w}_{n}\right)-H^{k-1}\left(\bar{w}_{n}\right)\right\|=0$. By combining with the uniform continuous on bounded subsets of $\nabla g$, we have $\lim _{n \rightarrow \infty}\left\|\nabla g\left(H^{k}\left(\bar{w}_{n}\right)\right)-\nabla g\left(H^{k-1}\left(\bar{w}_{n}\right)\right)\right\|=0$. This implies that $\lim _{n \rightarrow \infty}\left|\left\langle\nabla g\left(H^{k}\left(\bar{w}_{n}\right)\right)-\nabla g\left(H^{k-1}\left(\bar{w}_{n}\right)\right), v-H^{k}\left(\bar{w}_{n}\right)\right\rangle\right|=0$. By combining this with $\lim _{n \rightarrow \infty} H^{k}\left(\bar{w}_{n}\right)=p$, the lower semi-continuous property of $\varphi_{k}$, the continuity of $\psi_{k}$, we find that

$$
\varphi_{k}(v)-\varphi_{k}(p)+\left\langle\psi_{k}(p), v-p\right\rangle \geq f_{k}(v, p), \forall v \in \Omega
$$

and hence for all $v \in \Omega$, we have

$f_{k}(v, p)+\left\langle\psi_{k}(p), p-y\right\rangle+\varphi_{k}(p)-\varphi_{k}(v) \leq 0$.

For all $t \in(0,1]$, put $v_{t}=t v+(1-t) p$. Since $v, p \in \Omega$ and $\Omega$ is convex, we have $v_{t} \in \Omega$. Thus, replacing $v$ by $v_{t}$ in (3.30), we obtain

$$
f_{k}\left(v_{t}, p\right)+\left\langle\psi_{k}(p), p-v_{t}\right\rangle+\varphi_{k}(p)-\varphi_{k}\left(v_{t}\right) \leq 0 .
$$

Then, by using the condition (C1), the convexity in the second variable of $f$, the convexity of $\varphi$ and (3.31), we have

$$
\begin{aligned}
& 0=f_{k}\left(v_{t}, v_{t}\right) \\
& =f_{k}\left(v_{t}, v_{t}\right)+\left\langle\psi_{k}(p), v_{t}-v_{t}\right\rangle+\varphi_{k}\left(v_{t}\right)-\varphi_{k}\left(v_{t}\right) \\
& \leq t f_{k}\left(v_{t}, v\right)+(1-t) f_{k}\left(v_{t}, p\right)+t\left\langle\psi_{k}(p), v-v_{t}\right\rangle+(1-t)\left\langle\psi_{k}(p), p-v_{t}\right\rangle+t \varphi_{k}(v)+(1-t) \varphi_{k}(p)-\varphi_{k}\left(v_{t}\right) \\
= & t\left[f_{k}\left(v_{t}, v\right)+\left\langle\psi_{k}(p), v-v_{t}\right\rangle+\varphi_{k}(v)-\varphi_{k}\left(v_{t}\right)\right]+(1-t)\left[f_{k}\left(v_{t}, p\right)+\left\langle\psi_{k}(p), p-v_{t}\right\rangle+\varphi_{k}(p)-\varphi_{k}\left(v_{t}\right)\right] \\
& \leq t\left[f_{k}\left(v_{t}, v\right)+\left\langle\psi_{k}(p), y-v_{t}\right\rangle+\varphi_{k}(v)-\varphi_{k}\left(v_{t}\right)\right] .
\end{aligned}
$$

Since by $t \in(0,1]$, we have $f_{k}\left(v_{t}, v\right)+\left\langle\psi_{k}(p), v-v_{t}\right\rangle+\varphi_{k}(v)-\varphi_{k}\left(v_{t}\right) \geq 0$. Letting $t \rightarrow 0^{+}$and using the condition (C3), we have $f_{k}(p, v)+\left\langle\psi_{k}(p), y-p\right\rangle+\varphi_{k}(v)-\varphi_{k}(p) \geq 0$. This leads to $p \in \operatorname{GMEP}\left(f_{k}, \varphi_{k}, \psi_{k}\right)$ for each $k \in K$ and hence $p \in \bigcap_{k \in K} \operatorname{GMEP}\left(f_{k}, \varphi_{k}, \psi_{k}\right)$. Therefore,

$$
p \in \mathcal{F}=\left(\bigcap_{i \in I} F\left(S_{i}\right)\right) \cap\left(\bigcap_{k \in K} \operatorname{GMEP}\left(f_{k}, \varphi_{k}, \psi_{k}\right)\right) .
$$

Step 6. We claim that $p=P_{\mathcal{F}}^{g}\left(u_{1}\right)$. Indeed, since $u_{n+1}=P_{\Omega_{n+1}}^{g}\left(u_{1}\right)$, by Proposition 2.10, we have

$$
\left\langle\nabla g\left(u_{1}\right)-\nabla g\left(u_{n+1}\right), u_{n+1}-v\right\rangle \geq 0
$$


for all $v \in \Omega_{n+1}$. Let $u \in \mathcal{F}$. Since $\mathcal{F} \subset \Omega_{n+1}$, we have $u \in \Omega_{n+1}$. By choosing $v=u$ in (3.32), we get

$$
\left\langle\nabla g\left(u_{1}\right)-\nabla g\left(u_{n+1}\right), u_{n+1}-u\right\rangle \geq 0 .
$$

Taking the limit in the above inequality as $n \rightarrow \infty$, using $\lim _{n \rightarrow \infty} u_{n}=p$ and the uniform continuous on bounded subsets of $\nabla g$, we find that $\left\langle\nabla g\left(u_{1}\right)-\nabla g(p), p-u\right\rangle \geq 0$ for all $u \in \mathcal{F}$. By Proposition 2.11, we find that $p=P_{\mathcal{F}}^{g}\left(u_{1}\right)$.

In Theorem 3.1, by choosing $S_{i}=S$ for all $i \in I$ and $k \in K=\{1\}, f_{1}=f, \varphi_{1}=\varphi, \psi_{1}=\psi$, we obtain the following convergence result for a Bregman totally quasi-asymptotically nonexpansive mapping and a generalized mixed equilibrium problem in reflexive Banach spaces.

Corollary 3.2. Assume that $W$ is a real reflexive Banach space, and $\Omega$ is a nonempty, closed and convex subset of $W$, and $g: W \rightarrow \mathbb{R}$ is Legendre, strongly coercive on $W$, and $g$ is bounded, totally convex, uniformly Fréchet differentiable on bounded subsets of $W$. Let $f, \varphi, \psi$ satisfy the conditions (C1)-(C6) and $S: \Omega \rightarrow \Omega$ be a closed, uniformly asymptotically regular and Bregman totally quasiasymptotically nonexpansive mapping with nonnegative real sequences $\left\{\alpha_{n}\right\}$ and $\left\{\beta_{n}\right\}$ satisfying $\lim _{n \rightarrow \infty} \alpha_{n}=0, \quad \lim _{n \rightarrow \infty} \beta_{n}=0$ and strictly increasing continuous function $\zeta:[0, \infty) \rightarrow[0, \infty)$ with $\zeta(0)=0$ such that $\mathcal{F}=F(S) \cap G M E P(f, \varphi, \psi)$ is nonempty and bounded. Let $\left\{u_{n}\right\}$ be a sequence generated by

$$
\left\{\begin{array}{l}
u_{1}, v_{1} \in \Omega, \Omega_{1}=\Omega \\
w_{n}=\nabla g^{*}\left[a_{n} \nabla g\left(v_{n}\right)+\left(1-a_{n}\right) \nabla g\left(S^{n} u_{n}\right)\right] \\
v_{n+1}=\operatorname{Res}_{f, \varphi, \psi}^{g}\left(w_{n}\right) \\
\Omega_{n+1}=\left\{u \in \Omega_{n}: D_{g}\left(u, v_{n+1}\right) \leq a_{n} D_{g}\left(u, v_{n}\right)+\left(1-a_{n}\right) D_{g}\left(u, u_{n}\right)+\xi_{n}\right\} \\
u_{n+1}=P_{\Omega_{n+1}}^{g}\left(u_{1}\right), \forall n \geq 2
\end{array}\right.
$$

where $\xi_{n}=\left(1-a_{n}\right)\left[\alpha_{n} \sup \left\{\zeta\left(D_{g}\left(u, u_{n}\right)\right): u \in \mathcal{F}\right\}+\beta_{n}\right]$, the function $\operatorname{Res}_{f, \varphi, \psi}^{g}$ is defined as in Lemma 2.23 and $\left\{a_{n}\right\} \subset[0,1]$ such that $\lim _{n \rightarrow \infty} a_{n}=0$. Then the sequence $\left\{u_{n}\right\}$ strongly converges to $p=P_{\mathcal{F}}^{g}\left(u_{1}\right)$.

Note that if the Banach space $W$ is uniformly smooth, then $W$ is smooth and reflexive. By using Remark 2.7, from Theorem 3.1, we obtain the following convergence result for a finite family of totally quasi- $\phi$-asymptotically nonexpansive mappings and a system of generalized mixed equilibrium problems in uniformly smooth and strictly convex Banach spaces.

Corollary 3.3. Assume that $W$ is a uniformly smooth and strictly convex, and $\Omega$ is a nonempty, closed and convex subset of $W$. For each $k \in K:=\{1,2, \ldots, M\}$ with $M \in \mathbb{N}$, the functions $f_{k}, \varphi_{k}, \psi_{k}$ satisfy the conditions (C1)-(C6). For each $i \in I, \quad S_{i}: \Omega \rightarrow \Omega$ is a closed, uniformly asymptotically regular and totally quasi- $\phi$-asymptotically nonexpansive mapping with nonnegative real sequences $\left\{\alpha_{n}^{(i)}\right\}$ and $\left\{\beta_{n}^{(i)}\right\}$ satisfying $\lim _{n \rightarrow \infty} \alpha_{n}^{(i)}=\lim _{n \rightarrow \infty} \beta_{n}^{(i)}=0$ and strictly increasing continuous function $\zeta^{(i)}:[0, \infty) \rightarrow[0, \infty)$ with $\zeta^{(i)}(0)=0$ such that $\mathcal{F}=\left(\bigcap_{i \in I} F\left(S_{i}\right)\right) \cap\left(\bigcap_{k \in K} \operatorname{GMEP}\left(f_{k}, \varphi_{k}, \psi_{k}\right)\right)$ is nonempty and bounded. Let $\left\{u_{n}\right\}$ be a sequence generated by 


$$
\left\{\begin{array}{l}
u_{1}, v_{1} \in \Omega, \Omega_{1}=\Omega \\
w_{n}^{(i)}=J^{-1}\left[a_{n} J\left(v_{n}\right)+\left(1-a_{n}\right) J\left(S_{i}^{n} u_{n}\right)\right] \\
i_{n}=\arg \max \left\{\phi\left(u_{n}, w_{n}^{(i)}\right): i \in I\right\}, \bar{w}_{n}=w_{n}^{\left(i_{n}\right)} \\
v_{n+1}=H^{M}\left(\bar{w}_{n}\right) \\
\Omega_{n+1}=\left\{u \in \Omega_{n}: \phi\left(u, v_{n+1}\right) \leq a_{n} \phi\left(u, v_{n}\right)+\left(1-a_{n}\right) \phi\left(u, u_{n}\right)+\xi_{n}\right\} \\
u_{n+1}=\prod_{\Omega_{n+1}}\left(u_{1}\right), \forall n \geq 2
\end{array}\right.
$$

where $\xi_{n}=\left(1-a_{n}\right)\left[\alpha_{n} \sup \left\{\zeta\left(\phi\left(u, u_{n}\right)\right): u \in \mathcal{F}\right\}+\beta_{n}\right]$, the function $R_{k}:=\operatorname{Res}_{f_{k}, \varphi_{k}, \psi_{k}}^{g}$ is defined as in Lemma 2.24, where $\nabla g$ is replaced by $J, H^{k}=R_{k}\left(R_{k-1}\left(R_{k-2}\left(\ldots\left(R_{1}\right)\right)\right)\right)$ for all $k \in K,\left\{a_{n}\right\} \subset[0,1]$ such that $\lim _{n \rightarrow \infty} a_{n}=0$. Then the sequence $\left\{u_{n}\right\}$ strongly converges to $p=\prod_{\mathcal{F}}\left(u_{1}\right)$.

From Corollary 3.3, by choosing $S_{i}=S$ for all $i \in I$ and $k \in K=\{1\}, f_{1}=f, \varphi_{1}=\varphi, \psi_{1}=\psi$, we obtain the following convergence result for a totally quasi- $\phi$-asymptotically nonexpansive mapping and a generalized mixed equilibrium problems in uniformly smooth and strictly convex Banach spaces.

Corollary 3.4. Assume that $W$ is a uniformly smooth and strictly convex, and $\Omega$ is a nonempty, closed and convex subset of $W$. Let the functions $f, \varphi, \psi$ satisfy the conditions (C1)-(C6) and $S: \Omega \rightarrow \Omega$ be a closed, uniformly asymptotically regular and totally quasi- $\phi$-asymptotically nonexpansive mapping with nonnegative real sequences $\left\{\alpha_{n}\right\}$ and $\left\{\beta_{n}\right\}$ satisfying $\lim _{n \rightarrow \infty} \alpha_{n}=0, \lim _{n \rightarrow \infty} \beta_{n}=0$ and strictly increasing continuous function $\zeta:[0, \infty) \rightarrow[0, \infty)$ with $\zeta(0)=0$ such that $\mathcal{F}=F(S) \cap G M E P(f, \varphi, \phi) \neq \varnothing$ and bounded. Let $\left\{u_{n}\right\}$ be a sequence generated by

$$
\left\{\begin{array}{l}
u_{1}, v_{1} \in \Omega, \Omega_{1}=\Omega \\
w_{n}=J^{-1}\left[a_{n} J\left(v_{n}\right)+\left(1-a_{n}\right) J\left(S^{n} u_{n}\right)\right] \\
v_{n+1}=\operatorname{Res}^{g}\left(w_{n}\right) \\
\Omega_{n+1}=\left\{u \in \Omega_{n}: \phi\left(u, v_{n+1}\right) \leq a_{n} \phi\left(u, v_{n}\right)+\left(1-a_{n}\right) \phi\left(u, u_{n}\right)+\xi_{n}\right\} \\
u_{n+1}=\prod_{\Omega_{n+1}}\left(u_{1}\right), \forall n \geq 2
\end{array}\right.
$$

where $\xi_{n}=\left(1-a_{n}\right)\left[\alpha_{n} \sup \left\{\zeta\left(\phi\left(u, u_{n}\right)\right): u \in \mathcal{F}\right\}+\beta_{n}\right]$, the function $\operatorname{Res}_{f, \varphi, \psi}^{g}$ is defined as in Lemma 2.24, where $\nabla g$ is replaced by $J,\left\{a_{n}\right\} \subset[0,1]$ such that $\lim _{n \rightarrow \infty} a_{n}=0$. Then the sequence $\left\{u_{n}\right\}$ strongly converges to $p=\prod_{\mathcal{F}}\left(u_{1}\right)$.

Remark 3.5. (1) It follows from Remark 2.21 that each Bregman quasi-asymptotically nonexpansive mapping is a Bregman totally quasi-asymptotically nonexpansive mapping. Therefore, the conclusions in Theorem 3.1, Corollary 3.2 are hold when a Bregman totally quasi-asymptotically nonexpansive mapping is replaced by a Bregman quasi-asymptotically nonexpansive mapping. Similary, the conclusions in Corollary 3.3 and Corollary 3.4 are hold when a totally quasi- $\phi$-asymptotically nonexpansive mapping is replaced by a quasi- $\phi$-asymptotically nonexpansive mapping.

(2) Theorem 3.1 is an improvement of ([8], Theorem 4.1) from a generalized equilibrium and a Bregman relatively nonexpansive mapping to a finite family of Bregman totally quasi-asymptotically nonexpansive mappings and a system of generalized mixed equilibrium problems in reflexive Banach spaces.

(3) Corollary 3.3 and Corollary 3.4 are improvements of ([7], Theorem 3.1) from an equilibrium problem and a fixed point problem for an asymptotically quasi- $\phi$-nonexpansive mapping in intermediate sense to generalized mixed equilibrium problems and totally quasi- $\phi$-asymptotically nonexpansive mappings in uniformly smooth and strictly convex Banach spaces. 
Finally, we give an example to illustrate for Theorem 3.1. In the following example, the Bregman distance $D_{g}$ is not a norm and the Bregman projection is not a the generalized projection in smooth Banach spaces. Therefore, ([7], Theorem 3.1) cannot be applicable to the given mappings in Example 3.6.

Example 3.6. Let $W=\mathbb{R}, \Omega=[0,1], g(u)=u^{4}$ for all $u \in \mathbb{R}$. Then for all $u, w \in \mathbb{R}$, we have

$$
\nabla g(u)=4 u^{3}, \quad g^{*}(w)=3\left(\frac{w}{4}\right)^{4 / 3}, \quad \nabla g^{*}(w)=\left(\frac{w}{4}\right)^{1 / 3},
$$

$D_{g}(u, v)=u^{4}-v^{4}-4 v^{3}(u-v)=u^{4}+3 v^{4}-4 u v^{3}$.

For each $i \in I=\{1,2\}$, we consider $S_{i}(u)=\frac{u}{2^{i}}$ for all $u \in \Omega$. We have $F\left(S_{i}\right)=\{0\}$. Therefore, for $w \in F\left(S_{i}\right)$ and $u \in \Omega$, we obtain

$$
D_{g}\left(w, S_{i}^{n} u\right)=D_{g}\left(0, S_{i}^{n} u\right)=3\left(S_{i}^{n} u\right)^{4}=3\left(\frac{u}{2^{n i}}\right)^{4} \leq 3 u^{4}=D_{g}(0, u)=D_{g}(w, u) .
$$

This proves that $S_{i}$ is a Bregman totally quasi-asymptotically nonexpansive mapping with $\alpha_{n}^{(i)}=\beta_{n}^{(i)}=0$ for all $n \in \mathbb{N}^{*}$. For each $k \in K=\{1,2\}$, we consider

$f_{k}(u, v)=-u^{2}+u v, \varphi_{k}(u)=u^{2}, \psi_{k}(u)=u$ for all $u, v \in \Omega$. Then, by directly checking, we find that $f_{k}, \varphi_{k}, \psi_{k}$ satisfies the conditions (C1)-(C6). Now, we find the formula of $w=\operatorname{Res}_{f_{k}, \varphi_{k}, \psi_{k}}^{g}(u)$ for $u \in W, w \in \Omega$ as in Lemma 2.24. Indeed, $w=\operatorname{Res}_{f_{k}, \varphi_{k}, \psi_{k}}^{g}(u)$ if

$$
\operatorname{Res}_{f_{k}, \varphi_{k}, \psi_{k}}^{g}(u)=\left\{w \in \Omega: f_{k}(w, v)+\varphi_{k}(v)+\left\langle\psi_{k}(w), v-w\right\rangle+\langle\nabla g(w)-\nabla g(u), v-w\rangle \geq \varphi_{k}(w), \forall v \in \Omega\right\} .
$$

By substituting $f_{k}, \varphi_{k}, \psi_{k}, \nabla g$ into (3.33) and by directly calculating, we get

$$
v^{2}+\left(2 w+4 w^{3}-4 u^{3}\right) v+4 u^{3} w-4 w^{4}-3 w^{2} \geq 0 .
$$

Put $h(v)=v^{2}+\left(2 w+4 w^{3}-4 u^{3}\right) v+4 u^{3} w-4 w^{4}-3 w^{2}$ for all $v \in \Omega$. Then $h(v)$ is a quadratic function and $\Delta=\left(4 w+4 w^{3}-4 u^{3}\right)^{2}$. We consider the following cases.

Case 1. $\Delta>0$. Then the equation $h(v)=0$ has two solutions: $v_{1}=w$ and $v_{2}=4 u^{3}-4 w^{3}-3 w$. In order to $h(v) \geq 0$ for all $v \in \Omega$, we have following two cases:

Case 1.1. $v_{1}=1$ and $v_{1}<v_{2}$. Then $w=v_{1}=1, v_{2}=4 u^{3}-7>1$, and hence $u>\sqrt[3]{2}$.

Case 1.2. $v_{1}=0$ and $v_{2}<v_{1}$. Then $w=v_{1}=0$ and $v_{2}=4 u^{3}<0$. This leads to $u<0$.

Case 2. $\Delta \leq 0$. Then $w+w^{3}=u^{3}$ and $h(v) \geq 0$ for all $v \in \Omega$. From $w+w^{3}=u^{3}$, we get

$$
w=\frac{\left(\sqrt[3]{\sqrt{81 u^{6}+12}+9 u^{3}}\right)^{2}-\sqrt[3]{12}}{\sqrt[3]{18} \sqrt[3]{\sqrt{81 u^{6}+12}+9 u^{3}}}:=R(u) .
$$

Since $w \in \Omega$, we have $0 \leq u^{3} \leq 2$ and hence $0 \leq u \leq \sqrt[3]{2}$. Therefore,

$$
\operatorname{Res}_{f_{k}, \varphi_{k}, \psi_{k}}^{g}(u)=w=\left\{\begin{array}{cl}
0 & \text { if } u<0 \\
R(u) & \text { if } 0 \leq u \leq \sqrt[3]{2} \\
1 & \text { if } u>\sqrt[3]{2} .
\end{array}\right.
$$


By taking $a_{n}=\frac{1}{n+1}$, we have $\lim _{n \rightarrow \infty} a_{n}=0$. By the above, all assumptions in Theorem 3.1 are satisfied with the given functions $f_{k}, \varphi_{k}, \psi_{k}, S_{i}$. Therefore, by Theorem 3.1, the sequence $\left\{u_{n}\right\}$ which is defined by (3.1) converges to $0 \in \mathcal{F}=\left(\bigcap_{i \in I} F\left(S_{i}\right)\right) \cap\left(\bigcap_{k \in K} \operatorname{GMEP}\left(f_{k}, \varphi_{k}, \psi_{k}\right)\right)$.

Let $u_{1}=0.5, v_{1}=0.6, \Omega_{1}=\Omega$. It follows from directly calculating that the iterative process (3.1) becomes the following iteration.

$$
\left\{\begin{array}{l}
w_{n}^{(i)}=\frac{\left[4 a_{n} v_{n}^{3}+4\left(1-a_{n}\right) \frac{u_{n}^{3}}{2^{3 n i}}\right]^{1 / 3}}{\sqrt[3]{4}}, \forall i=1,2 \\
i_{n}=\arg \max \left\{u_{n}^{4}+3\left(w_{n}^{(i)}\right)^{4}-4 u_{n}\left(w_{n}^{(i)}\right)^{3}: i=1,2\right\} \\
\bar{w}_{n}=w_{n}^{\left(i_{n}\right)}, v_{n+1}=R\left(R\left(\bar{w}_{n}\right)\right) \\
u_{n+1}=\frac{3 a_{n} v_{n}^{4}+3\left(1-a_{n}\right) u_{n}^{4}-3 v_{n+1}^{4}}{4 a_{n} v_{n}^{3}+4\left(1-a_{n}\right) u_{n}^{3}-4 v_{n+1}^{3}}, \forall n \geq 2 .
\end{array}\right.
$$

By using Scilab-6.0 software for calculating the numerical result of the iteration (3.34), we find that $\left\{u_{n}\right\}$ approximates to 0 when $n=54$ and $\left\|u_{n}-0\right\|<10^{-7}$. The convergence behavior of the iteration (3.34) is presented by the following figure.

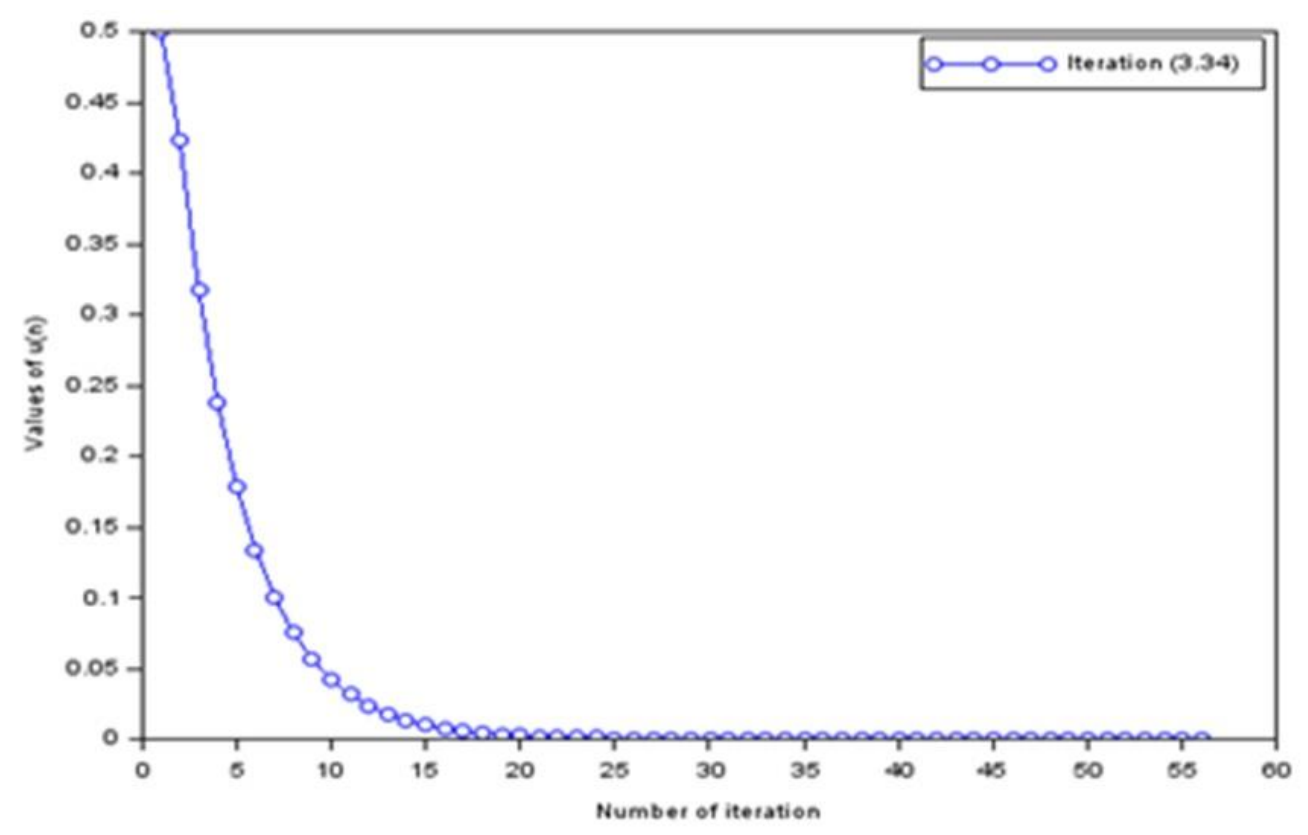

Figure 1: The convergence behavior of the iteration $\left\{\boldsymbol{u}_{\boldsymbol{n}}\right\}$ generated by (3.34) to 0 .

\section{Conclusion}

In this paper, a hybrid iterative method is proposed for solving a finite system of generalized mixed equilibrium problems and common fixed point problem of a finite family of Bregman totally quasi-asymptotically nonexpansive mappings reflexive Banach spaces. Furthermore, a strong 
convergence theorem for the proposed iteration is proved in reflexive Banach spaces. As application, we obtain some convergence results for generalized mixed equilibrium problems and totally quasi- $\phi$ asymptotically nonexpansive mappings in uniformly smooth and strictly convex Banach spaces. In addition, a numerical example is given to illustrate for the obtained results. These results generalize and extend the main results in $[7,8]$.

\section{Acknowledgment}

The author would like to thank the Ministry of Education and Training, Vietnam for the funding under the project B2021.SPD.02 during the revision of this manuscript.

\section{Conflict of Interest}

There are no potential conflicts of interest with respect to the research, authorship, and publication of this article.

\section{References}

[1] A. Ambrosetti and G.Prodi, A Primer of nonlinear analysis. Cambridge studies in Advanced Mathematics, Cambridge University Press, 1993.

[2] D. Butnariu and A. N. Iusem, Totally convex functions for fixed points computation and infinite dimensional optimization, Applied optimization, vol. 40, Kluwer Academic, Dordrecht, 2000.

[3] D. Butnariu and E. Resmerita, "Bregman distances, totally convex functions and a method for solving operator equations in Banach spaces," Abstr. Appl. Anal., pp.1-39, 2006.

[4] Y. Censor and A. Lent, "An iterative row-action method for interval convex programming," J. Optim. Theory Appl., 34, pp.321-353, 1981.

[5] S. S. Chang, L. Wang, X. R. Wang, and C. K. Chan, "Strong convergence theorems for Bregman totally quasi-asymptotically nonexpansive mappings in reflexive Banach spaces," Appl. Math. Comput., 228, pp.38-48, 2014.

[6] V. Darvish, "Strong convergence theorem for generalized mixed equilibrium problems and Bregman nonexpansive mapping in Banach spaces," Math. Morav., 20(1), pp.69-87, 2016.

[7] K. R. Kazmi and R. Ali, Common solution to an equilibrium problem and a fixed point problem for an

asymptotically quasi- -nonexpansive mapping in intermediate sense," Rev. R. Acad. Cienc. Exactas Fi's. Nat. Ser. A Mat. RACSAM, 111(3), pp.877-899, 2017.

[8] K. R. Kazmi, R. Ali, and S. Yousuf, "Generalized equilibrium and fixed point problems for Bregman relatively nonexpansive mappings in Banach spaces", J. Fixed Point Theory Appl., 20:151, pp.1-21, 2018.

[9] F. Kohsaka and W.Takahashi, "Proximal point algorithms with Bregman functions in Banach spaces," J. Nonlinear Convex Anal., 6(3), pp.505-523, 2005.

[10] W. Kumam, U. Witthayarat, P. Kumam, S. Suantai, and K. Wattanawitoon, “Convergence theorem for equilibrium problem and Bregman strongly nonexpansive mappings in Banach spaces," Optimization, 65(2), pp.265-280,2016.

[11] X. Naraghirad and J. C. Yao, "Bregman weak relatively nonexpansive mappings in Banach spaces,” Fixed Point Theory Appl., 2013(141), pp.1-43, 2013. 
[12] J .W. Peng and J . C. Yao, "A new hybrid-extragradient method for generalized mixed euqilibrium problems, fixed point problems and variational inequality problems", Taiwanese J. Math., 12, pp.1401-1432, 2008.

[13] S. Reich and S. Sabach, "Two strong convergence theorems for a proximal method in reflexive Banach spaces," Numer. Funct. Anal. Optim., 31, pp.22-44, 2010.

[14] S. Reich and S. Sabach, "A strong convergence theorem for a proximal-type algorithm in reflexive Banach spaces", J. Nonlinear Convex Anal., 10, pp.471-485, 2009.

[15] E. Resmerita, "On total convexity, Bregman projections and stability in Banach spaces," J. Nonlinear Convex Anal., 11, pp.1-16, 2004.

[16] S. Sabach, "Products of finitely many resolvents of maximal monotone mappings in reflexive Banach spaces," SIAM J. Optim., 21, pp.1289-1308, 2011.

[17] Z. Zalinescu, Convex analysis in general vector spaces, World Scientific, River Xdge, 2002.

[18] S. Zhu and J. H. Huang, "Strong convergence theorems for equilibrium problem and Bregman totally quasi-asymptotically nonexpansivemapping in Banach spaces," Acta Math. Sci. Ser. B, 36B(5), pp.1433-1444, 2016. 